\title{
Individual differences in spatial utilization of a river-system by otters Lutra lutra
}

\author{
Leon S. DURBIN
}

\begin{abstract}
Durbin L. S. 1996. Individual differences in spatial utilization of a river-system by otters Lutra lutra. Acta Theriologica 41: 137-147.

One female and 2 male otters Lutra lutra (Linnaeus, 1758) were radio-tracked in the River Don catchment, Aberdeenshire, Scotland, between April 1988 and June 1990, and their range use patterns were compared. The males had longer total ranges than the female. The range of the larger male almost completely overlapped with that of the female, but the range of the smaller male was mainly separate from that of the female. The ranges of the 2 males only partially overlapped, with the larger male having the greatest total range, nightly range and rate of travel, and the lowest tendency to revisit areas during the night. The smaller male was relatively sedentary, using two separate core areas, whereas the other 2 otters had single core areas and frequently patrolled their total ranges. As the larger male was sexually active, but the smaller one did not appear to be, it was argued that the need to search for mates could explain some of these differences in spatial patterns. All 3 otters used tributaries more than expected based on the areas within their total ranges. This may be because riparian margins were used in greater proportion than central areas of the channel
\end{abstract} width.

Institute of Terrestrial Ecology, Banchory, Kincardineshire, Scotland AB31 4BY

Key words: Lutra lutra, spatial utilization, river, ranges, radio-tracking

\section{Introduction}

Since the widespread decline of the otter Lutra lutra (Linnaeus, 1758) in the late $1950 \mathrm{~s}$, the species has failed to recolonise many parts of Western Europe (Foster-Turley et al. 1990). Although patterns of home range use have important effects on otter density, data on spatial utilization are rare, especially for freshwater habitats. Furthermore, some of the available information may be subject to biases. For example, Erlinge's (1967, 1968) snow-tracking study in a Swedish lake-system may have involved problems in distinguishing between individuals or even age-sex cohorts, as well as difficulties in tracking otters in certain habitats. Similarly, the use of visual observations in marine habitats (eg Kruuk and Moorhouse 1991) may bias estimates of range use towards areas where animals are easier to see and where more observer effort is expended. There have been only 2 published studies making more systematic observations using radio-telemetry (rivers: Green et al. 1984, Kruuk et al. 1993), but neither of them examined range use in detail. 
From these various studies it appears that otters forage alone, except when a female is accompanied by her cubs. Range use is strongly affected by food availability (Kruuk et al. 1993). There may be intra-sexual spacing (Erlinge 1968, Kruuk and Moorhouse 1991), and adult males often occupy larger ranges than females (Erlinge 1967, Green et al. 1984, Kruuk and Moorhouse 1991, Kruuk et al. 1993). These patterns are common to many animals, particularly mustelids (Powell 1979). There remains, however, a lack of information about individual differences in habitat use, particularly with respect to short-term and long-term movement patterns.

The main reasons for the paucity of detailed observations using radio-telemetry are that animals usually live at low densities, are trap-shy, often nocturnal, and occupy extensive ranges (Kruuk et al. 1993). Nevertheless, in the present study 3 otters were radio-tracked in the River Don, North-east Scotland; 2 of them for more than a year. These observations allow a rigorous and detailed assessment of range use patterns. The specific aims of the study are to determine: (1) total and nightly range sizes, (2) spatial and temporal patterns of range use, (3) whether the ranges are used linearly, or in proportion to their area, and (4) rates of travel and tendencies to revisit areas during the night. Possible factors affecting these patterns, and differences between individuals, are discussed.

\section{Methods}

\section{Study area}

The River Don (ca $140 \mathrm{~km}$ long) in Aberdeenshire, Scotland has its source in the Ladder Hills (Ordinance Survey G.R. NJ195066: $670 \mathrm{~m}$ a.s.l.) and its outflow to the North Sea at Aberdeen (G.R. NJ955096). The study area extended from Alford (G.R. NJ554169: ca $50 \mathrm{~km}$ from mouth) to Glenkindie (G.R. NJ400149: ca $80 \mathrm{~km}$ from mouth). Within this area the river and tributaries were mostly fast-flowing (ie predominantly riffle) and oligotrophic, with eroding substrates. The mean width of the river was $21 \mathrm{~m}(n=150$, range $14-40 \mathrm{~m})$, and that of streams was $2 \mathrm{~m}(n=162$, range $0.2-8 \mathrm{~m}$ ).

The area was mostly covered by pasture, arable fields and coniferous forestry plantations, but there were also some deciduous woodlands, and moorland. Fish species were dominated by salmonids - brown trout Salmo trutta (including migratory sea trout) and Atlantic salmon S. salar, but there were also eel Anguilla anguilla, three-spined stickleback Gasterosteus aculeatus, and minnow Phoxinus phoxinus.

\section{Study animals}

Three otters were caught in box traps, anaesthetized, and implanted intra-peritoneally (see Melquist and Hornocker 1983) with $25 \mathrm{~g}$ radio-transmitters (field range $0.8 \mathrm{~km}$ ). Subsequent radio-tracking showed that 2 of these animals were sexually active: male M2 $(8.0 \mathrm{~kg})$ was seen mating and female F1 $(5.8 \mathrm{~kg})$ gave birth. Male M1 $(7.0 \mathrm{~kg})$ was also independent, but his sexual status was unknown. None of the animals showed noticable signs of dental decay which, in addition to their general appearances, suggested that they were not very old. Furthermore, a condition index based on the animal's weight relative to its length (see Kruuk et al. 1987) suggested that the otters were not under-nourished (for values see Durbin 1993). 


\section{Radio-tracking}

A total of $1372 \mathrm{~h}$ were spent radio-tracking between April 1988 and June 1990, which included $693 \mathrm{~h}$ of otter activity (Table 1). Otters M2 and F1 were each tracked for a year, but as M1's radio failed prematurely it was tracked for only 10 weeks. Only during June and July 1989 were 2 of the animals tracked concurrently.

Because the otters were generally nocturnal (L. Durbin, unpubl.) nearly all tracking occurred at night. Each 'session' (the tracking period for a particular night) was classified as either 'complete' (from emergence at dusk, to retirement at dawn), or 'partial' (usually a $4 \mathrm{~h}$ session with an arbitrary start time). Radio-locations (to within $100 \mathrm{~m}$ accuracy) were taken every $15 \mathrm{~min}$, with additional locations when animals changed their activity, or direction of travel. Activity in the water could be clearly distinguished from that on the bank because of characteristic signal fluctuations. Activity was classified as 'social' when vocalisations were heard, or if adult animals were seen together. In this study the locations where two animals happened to meet were considered to be of less spatial significance than foraging locations. Consequently, social interactions were excluded from calculations of range use and movement parameters (see below), as they would have obscured such foraging patterns. Furthermore, the differences between movement parameters, before and after interactions were of greater interest (because of possible effects of meetings on subsequent mate-searching behaviour) than the localised activity occurring during such meetings.

Table 1. Radio-tracking effort.

\begin{tabular}{|c|c|c|c|c|c|c|}
\hline \multirow{2}{*}{ Animal } & \multirow{2}{*}{$\begin{array}{l}\text { Tracking dates } \\
\text { (mon/yr) }\end{array}$} & \multirow{2}{*}{$\begin{array}{l}\text { Tracking period } \\
\text { (h) }\end{array}$} & \multirow{2}{*}{$\begin{array}{l}\text { Otter activity } \\
\text { (h) }\end{array}$} & \multicolumn{3}{|c|}{ Nights tracked } \\
\hline & & & & partial & complete & total \\
\hline F1 & $8 / 88-7 / 89$ & 678 & 261 & 107 & 18 & 125 \\
\hline M1 & $4 / 88-7 / 88$ & 251 & 189 & 20 & 25 & 45 \\
\hline M2 & $6 / 89-6 / 90$ & 443 & 243 & 84 & 13 & 97 \\
\hline
\end{tabular}

\section{Analysis of range size and use}

'Total range' was defined as the length of waterway used by an otter during radio-tracking. Each of these ranges was divided into the river (main stem) and streams (tributaries), then subdivided into $200 \mathrm{~m}$ sections. The total recorded number of visits by an otter to these sections provided a measure of the intensity of range use. Because there were no clear discontinuities in the frequency distributions of visits to sections, 'core sections' were simply defined as those that were visited more than average by an otter. A 'core area' was a continuous length of core sections, and the 'total core area' was the sum of all core areas within the total range.

The total lengths and areas of river and streams used by each animal were calculated (see Kruuk et al. 1993). As radio-locations were auto-correlated, tracking sessions were taken as the independent units of range use. In each session an otter spent its active time either predominantly in the river, or in the streams. An otter's use of the river and streams was therefore quantified as the number of sessions predominating in each. Had an otter used these regions in proportion to the lengths they represent within its range, the expected number of sessions predominating in each region would have been,

$$
\mathrm{SE}^{\mathrm{L}}=\mathrm{SH}^{\mathrm{L}} / \mathrm{R}^{\mathrm{L}}
$$

and if used in proportion to the areas within its range, the expected value would have been,

$$
\mathrm{SE}^{\mathrm{A}}=\mathrm{SH}^{\mathrm{A}} / \mathrm{R}^{\mathrm{A}} \text {, }
$$


where $\mathrm{S}$ is the total number of sessions spent tracking the otter, $\mathrm{H}^{\mathrm{L}}$ or $\mathrm{A}$ is the length or area of river or stream habitat within the otter's range, and $\mathrm{R}^{\mathrm{L} \text { or } \mathrm{A}}$ is the length or the area of the otter's total range (White and Garrott 1990).

The actual numbers of sessions predominating in the river and streams were then compared with those predicted by the proportional use of length and area (White and Garrott 1990). In this analysis, the use of the river and streams was considered simultaneously, to avoid the problem of dependence when the proportional use of a habitat type is treated separately (Aebischer and Robertson 1992). Chi-square analysis was used to test for goodness-of-fit (Neu et al. 1974, Alldredge and Ratti 1986).

During visual observations of foraging in the river, the otters position for the first sighting of the session was classified as either at the 'margins' ( $<1 \mathrm{~m}$ from the bank), or in the 'centre' ( $>1 \mathrm{~m}$ from bank). These observations were used to compare the otters' relative use of these zones.

\section{Movement parameters}

The following movement parameters were calculated for each tracking session: rate of travel = $\mathrm{D} / \mathrm{T}$, rate of range use $=\mathrm{L} / \mathrm{T}$, and revisit index $=\mathrm{D} / \mathrm{L}$, where $\mathrm{D}$ is the total distance travelled by the otter (including revisited areas), $\mathrm{T}$ is the time that it spent active (excluding social interactions and time spent out of the water), and $L$ is the length of range that it used. Means of these parameters (over all sessions) were calculated for the total range, and separately for the river and streams.

\section{Results}

In preliminary analyses, data from before and after $\mathrm{F} 1$ gave birth were compared, but as there were few differences and these have been discussed elsewhere (Durbin, in press), data were pooled for the present analyses.

\section{Range size and use}

All 3 otters showed asymptotic range expansion (Fig. 1), suggesting that longer study periods would have had minimal effect on total range estimates (Mares et

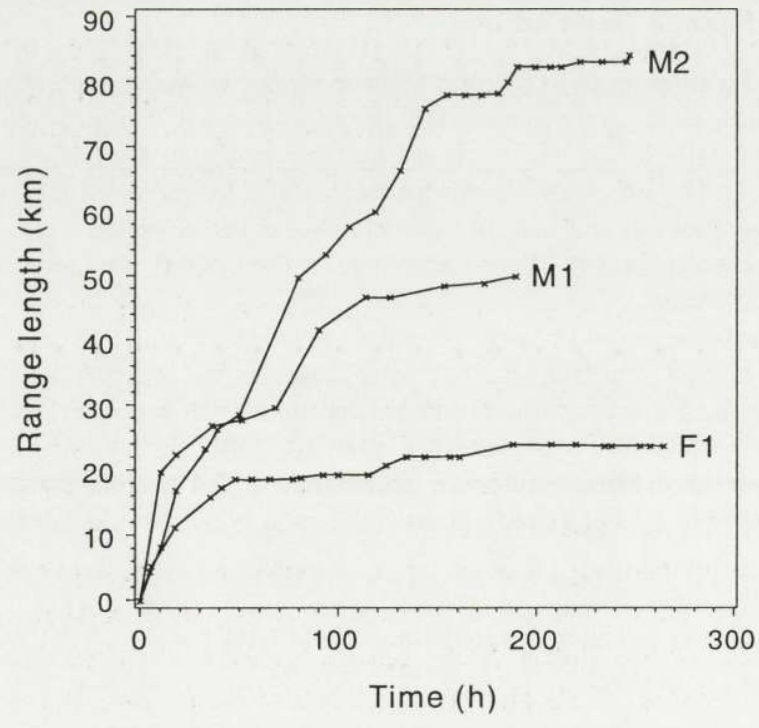

Fig. 1. Cumulative plots of range length against the total periods of otter activity during radio-tracking. 
Table 2. (a) Dimensions of total range (TR) and total core area (TCA). (b) The spatial overlap of these regions between pairs of otters.

\begin{tabular}{|c|c|c|c|c|c|c|c|c|c|c|c|}
\hline \multicolumn{7}{|c|}{ (a) } & \multicolumn{5}{|c|}{ (b) Overlap of: } \\
\hline \multirow{2}{*}{ Animal } & \multicolumn{3}{|c|}{ Length $(\mathrm{km})$} & \multicolumn{3}{|c|}{ Area (ha) } & \multirow{2}{*}{$\begin{array}{c}\text { Animals } \\
\text { compared }\end{array}$} & \multicolumn{2}{|c|}{ TR } & \multicolumn{2}{|c|}{ TCA } \\
\hline & TR & TCA & TCA/TR & TR & TCA & TCA/TR & & $(\mathrm{km})$ & $(\%: \%)$ & $(\mathrm{km})$ & $(\%: \%)$ \\
\hline F1 & 24.0 & 10.2 & 0.42 & 33.5 & 21.6 & 0.65 & F1:M1 & 3.2 & $13: 6$ & 0.4 & $4: 2$ \\
\hline M1 & 50.2 & 18.8 & 0.37 & 28.6 & 14.9 & 0.52 & F1:M2 & 19.6 & $81: 23$ & 9.2 & $90: 26$ \\
\hline M2 & 84.4 & 35.6 & 0.42 & 78.7 & 62.8 & 0.80 & M1:M2 & 18.2 & $36: 21$ & 2.8 & $15: 8$ \\
\hline
\end{tabular}

Table 3. Mean (SD) nightly range sizes and activity periods during complete nights of tracking $(n)$.

\begin{tabular}{lcccc}
\hline Animal & \multicolumn{3}{c}{ Nightly } & $\begin{array}{c}\text { \% of total range } \\
\text { used/night }\end{array}$ \\
\cline { 2 - 4 } & $n$ & Range $(\mathrm{km})$ & Activity period (h) & \\
\hline F1 & 18 & $5.9(1.7)$ & $4.2(0.9)$ & 25 \\
M1 & 25 & $6.5(2.6)$ & $5.2(1.3)$ & 13 \\
M2 & 13 & $9.9(4.3)$ & $4.6(0.9)$ & 12 \\
\hline
\end{tabular}

al. 1980). Although M1 had a shorter study period than the other 2 otters, the total lengths of time that the otters were recorded active during their study periods were similar (Table 1). The 2 males had longer total ranges than the female (Table 2 ), and the area of M2's range was also greater than her's. The area of M1's range, however, was similar to the female's.

The nightly activity periods of the 2 males were similar, but that of M1 was significantly longer than F1's (Wilcoxon: $Z=-2.4, p<0.05$; Table 3). Despite their different nightly activity periods, $\mathrm{F} 1$ and $\mathrm{M} 1$ used similar nightly range lengths (Wilcoxon: $Z=0.7, \mathrm{~ns}$ ). M2, however, had a longer nightly range than either of the other otters ( $\mathrm{F} 1: Z=3.2, \mathrm{M} 1: Z=2.5, p<0.05)$. Intensity of range use is represented in Fig. 2. During M1's relatively short study period he used two distinct core areas, whereas M2 and F1 used single core areas (apart from short gaps in that of M2), and showed greater homogeneity of core use than M1 (Fig. 2). There were also differences in temporal range use patterns. M1 alternated between his two core areas only twice during the time he was studied, spending several weeks in each area. F1 and M2, however, regularly travelled between their range boundaries, visiting areas throughout their total ranges.

The otters were rarely tracked concurrently, however, the spatial overlap of their total ranges and total core areas were measured (Table 2b), assuming that these patterns were stable in time (see Discussion). M2's range almost completely overlapped with the female's range, whereas M1's range was almost separate from 

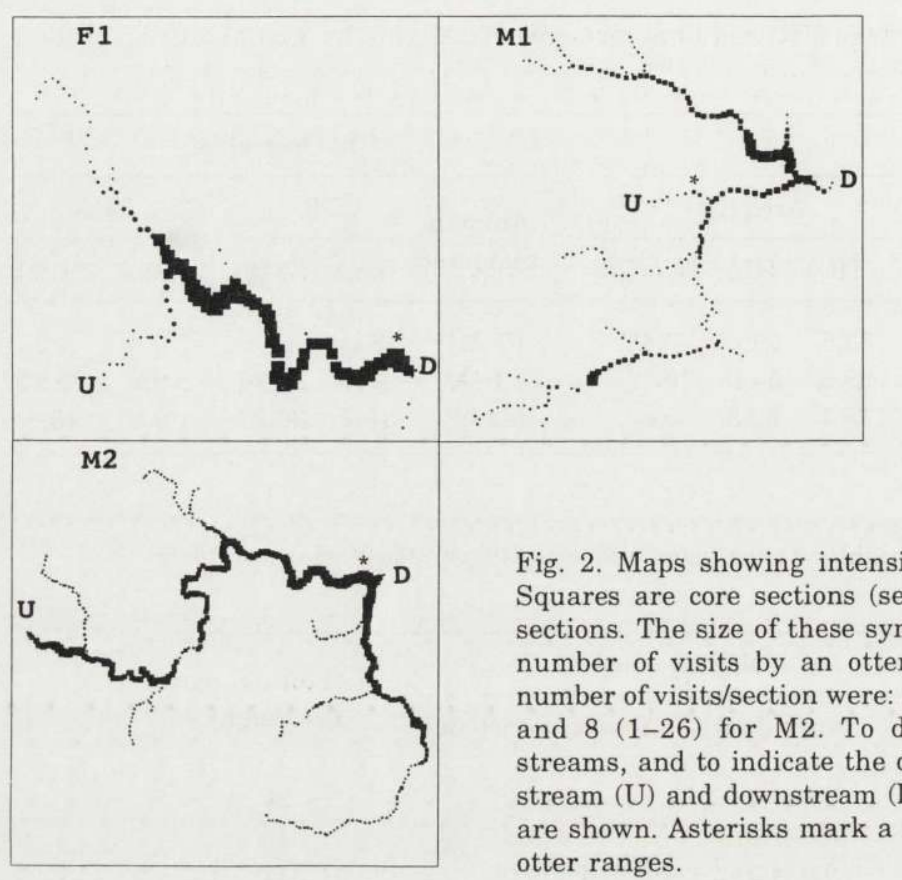

Fig. 2. Maps showing intensity of total range use by otters. Squares are core sections (see text) and circles are non-core sections. The size of these symbols is proportional to the total number of visits by an otter to each section. Mean (range) number of visits/section were: 22 (1-69) for F1, 6 (1-34) for M1 and $8(1-26)$ for M2. To distinguish between river and streams, and to indicate the direction of current flow, the upstream (U) and downstream (D) range boundaries on the river are shown. Asterisks mark a reference point common to the 3 otter ranges.

that of the female. The total core areas of M1 and F1 showed proportionally less overlap than their ranges. The ranges of the two males overlapped only partially, and their core areas overlapped proportionally less than their ranges.

\section{Use of rivers and streams}

The total ranges of all 3 otters comprised a greater area of river than stream. Those of the males, however, comprised a greater length of stream than river, whereas the length of the female's range was almost equally divided between river and stream (Table 4). Each otter used the streams more than expected based on the areas within its range $\left(\mathrm{F} 1: \chi^{2}=4.3, \mathrm{df}=1, p<0.05 ; \mathrm{M} 1: \chi^{2}=10.4, \mathrm{df}=1\right.$, $p<0.01 ; \mathrm{M} 2: \chi^{2}=12.1, \mathrm{df}=1, p<0.01$; Table 4). The 2 males, however, used the river and streams in proportion to the lengths within their ranges, whereas the female used the river in greater proportion than the length available $\left(\chi^{2}=28.4\right.$, $\mathrm{df}=1, p<0.001$ ). The males, therefore, used their ranges in a more linear fashion than the female.

As the range use of each otter was disproportionate to the areas available, it was possible that a linear habitat feature such as the stream-bank interface was preferred by them. Sightings were used to examine this, but because these were few, data from all 3 individuals were pooled. A higher proportion of these sightings (59\%, $n=59$ ) were at the river margins than would have been expected had the width been used uniformly (ca $9 \%$ of width $=$ 'margins') $\left(\chi^{2}=31.3, \mathrm{df}=1, p<0.001\right.$ ). 
Table 4. Percentage of tracking sessions spent predominantly in the river or the streams, and the percentages expected had the otters used these regions in proportion to the areas or lengths within their ranges. See Table 1 for numbers of tracking sessions, and Table 3 for the lengths and areas of the total ranges. $\chi^{2}$-tests compare the number of sessions predominating, with relative frequencies based on the areas or lengths available. Significance: ${ }^{*}-p<0.05$ ** $-p<0.01, * * *-p<0.001$, ns - not significant.

\begin{tabular}{llccc}
\hline Animal & Habitat & Area (\%) & Length (\%) & Sessions (\%) \\
\hline F1 & river & 94 & 52 & 82 \\
& streams & 6 & 48 & 22 \\
& & $*$ & $* * *$ & \\
M1 & river & 63 & 11 & 16 \\
& streams & 37 & 89 & 84 \\
& & $* *$ & ns & \\
M2 & river & 84 & 37 & 51 \\
& streams & 16 & 63 & 49 \\
& & $* *$ & ns & \\
\hline
\end{tabular}

\section{Movement parameters}

Nightly movements were examined by analysing travel rates, range use rates, and the tendency of animals to revisit areas during tracking sessions. The smaller male M1 showed no differences in his movement parameters between the river and streams (Table 5). The female, however, had higher rates of travel (Wilcoxon: $Z=2.9, p<0.05)$ and nightly range use $(Z=2.7, p<0.05)$ in the streams than in the river. By contrast, M2 travelled faster in the river than in the streams

Table 5. Mean (SD) nightly movement parameters of the individual otters (a) for their total ranges and (b) by habitat. Wilcoxon two-sample tests compare parameters for river and streams. Significance: $*-p<0.05, \mathrm{~ns}-$ not significant.

\begin{tabular}{|c|c|c|c|c|c|c|}
\hline & Animal & Habitat & $\begin{array}{c}\text { No of nights } \\
\text { tracked }\end{array}$ & $\begin{array}{l}\text { Travel rate } \\
(\mathrm{km} / \mathrm{h})\end{array}$ & $\begin{array}{l}\text { Range use } \\
\text { rate }(\mathrm{km} / \mathrm{h})\end{array}$ & Revisit index \\
\hline \multirow[t]{3}{*}{ (a) } & F1 & & 125 & $2.4(1.9)$ & $2.0(1.9)$ & $1.3(0.4)$ \\
\hline & M1 & & 45 & $1.8(0.6)$ & $1.4(0.6)$ & $1.3(0.3)$ \\
\hline & M2 & & 97 & $2.9(1.2)$ & $2.6(1.1)$ & $1.2(0.3)$ \\
\hline \multirow[t]{6}{*}{ (b) } & F1 & river & 120 & $2.4(2.0)$ & $2.1(2.0)$ & $1.3(0.4)$ \\
\hline & & stream & 74 & $\begin{array}{c}3.2(2.2) \\
*\end{array}$ & $\begin{array}{c}2.7(1.9) \\
*\end{array}$ & $\begin{array}{c}1.3(0.4) \\
n s\end{array}$ \\
\hline & M1 & river & 20 & $2.2(1.1)$ & $1.8(1.1)$ & $1.3(0.3)$ \\
\hline & & stream & 45 & $\begin{array}{c}1.8(0.8) \\
\mathrm{ns}\end{array}$ & $\begin{array}{c}1.6(0.8) \\
\mathrm{ns}\end{array}$ & $\begin{array}{c}1.3(0.3) \\
\mathrm{ns}\end{array}$ \\
\hline & M2 & river & 69 & $3.6(4.1)$ & $3.3(4.0)$ & $1.2(0.3)$ \\
\hline & & stream & 73 & $\begin{array}{c}3.2(2.5) \\
*\end{array}$ & $\begin{array}{c}2.9(2.5) \\
\mathrm{ns}\end{array}$ & $\begin{array}{c}1.1(0.3) \\
n s\end{array}$ \\
\hline
\end{tabular}


Table 6. Results of Wilcoxon two-sample tests ( $Z$ values) comparing nightly movement parameters between pairs of otters. Significance: ${ }^{*}-p<0.05,{ }^{* * *}-$ $p<0.001, \mathrm{~ns}-$ not significant.

\begin{tabular}{llccc}
\hline & Otters & \multicolumn{3}{c}{ Habitat } \\
\cline { 3 - 5 } Parameter & compared & River & Stream & Combined \\
\hline \multirow{2}{*}{ Travel rate } & M1:M2 & $-4.1^{* * *}$ & $-5.0^{* * *}$ & $-6.8^{* * *}$ \\
& F1:M2 & $6.3^{* * *}$ & $0.2 \mathrm{~ns}$ & $5.7 * * *$ \\
& F1:M1 & $0.2 \mathrm{~ns}$ & $-4.0^{* * *}$ & $-2.1^{*}$ \\
Range use rate & M1:M2 & $-4.1 * * *$ & $-5.0 * * *$ & $-6.5^{* * *}$ \\
& F1:M2 & $5.7 * * *$ & $1.0 \mathrm{~ns}$ & $6.0^{* * *}$ \\
& F1:M1 & $-0.4 \mathrm{~ns}$ & $-3.7 * * *$ & $-2.0^{*}$ \\
Revisit index & M1:M2 & $0.9 \mathrm{~ns}$ & $3.9 * * *$ & $3.5 * * *$ \\
& F1:M2 & $-1.4 \mathrm{~ns}$ & $-1.1 \mathrm{~ns}$ & $-2.6 *$ \\
& F1:M1 & $0.1 \mathrm{~ns}$ & $2.2 *$ & $1.2 \mathrm{~ns}$ \\
\hline
\end{tabular}

$(Z=2.6, p<0.05)$. Male M2's range use rates were generally higher than those of the other 2 otters as he travelled faster than they did, and was less likely to return to areas during tracking sessions (Tables 5 and 6). When using streams, his travel rate was similar to that of the female. In the river, all animals had similar tendencies to revisit areas during sessions. When in the streams, M1 returned to areas more often and had lower rates of travel and range use than the other 2 animals.

As social interactions (often signalled by 'whickering' vocalisations) may have influenced movement patterns (particularly for males seeking mates), the frequency of meetings was compared. Separate, vocal meetings were heard less frequently whilst tracking otter M1 (0.01 meetings/h of activity) than for M2 $\left(0.09 / \mathrm{h}\right.$ : analysis of sessions, $\left.\chi^{2}=4.9, \mathrm{df}=1, p<0.05\right)$, or $\mathrm{F} 1\left(0.08 / \mathrm{h}: \chi^{2}=5.9, \mathrm{df}=1\right.$, $p<0.05$ ), despite consistent tracking procedures. Many of the interactions seen while tracking M2 and F1 were protracted (10-120 min), and included apparent sexual behaviour (eg mounting and mutual grooming), but M1 was recorded in only 2 , brief $(<2 \mathrm{~min})$, non-sexual interactions.

To examine the effect of social factors on the nightly movements, the 3 parameters were compared for each animal (excluding time spent in interactions) during tracking sessions with and without vocal meetings. The only significant differences were that M2 had lower rates of travel and nightly range use for sessions with meetings $(n=21)$ than for sessions without $(n=169)$. His mean travel rate during sessions with meetings was only $2.7 \pm 1.5(\bar{x} \pm \mathrm{SD}) \mathrm{km} / \mathrm{h}$, compared to $3.2 \pm 3.1 \mathrm{~km} / \mathrm{h}$ for those without (Wilcoxon: $Z=-3.5, p<0.001$ ). Similarly, his rate of range use was only $2.0 \pm 1.2 \mathrm{~km} / \mathrm{h}$ for sessions with meetings, and $2.9 \pm 3.1 \mathrm{~km} / \mathrm{h}$ for those without $(Z=-4.0, p<0.001)$. For the sessions when interactions occurred, however, there was no difference in these rates before and after the meetings. 


\section{Discussion}

In common with previous otter studies (Erlinge 1967, Kruuk and Moorhouse 1991, Green et al. 1984, Kruuk et al. 1993), the 3 otters used extensive total ranges, the males with longer ones than the female. Male M2's range also had a greater area than that of the female, but M1's range had an area similar to her's. This difference in the range sizes of the 2 males could reflect an apparent difference in their sexual activity. As Eurasian otters are polygamous (Chanin 1985), and in most cases females are continually polyestrous unless fertilised (Gorman and Trowbridge 1989), a reproductive male would probably require a larger range than an immature one, in order to maximise encounters with females (Sandell 1989). In the present study, M1, with the smaller range, had proportionally fewer vocal interactions than M2, and none of M1's meetings were overtly sexual, contrary to those of M2. In addition, the range of M2 almost completely overlapped with that of the sexually active female $\mathrm{F} 1$ and was sufficient to have encompassed 3 ranges the length of her's. Furthermore, his range may have contained more than 3 females if spatial organisation was similar to that along the coasts of Shetland (Kruuk and Moorhouse 1991). By contrast, the ranges of M1 and F1 were almost separate, but this male's range could well have overlapped with the ranges of unmarked females. Although these patterns of overlap were based on otters tracked during largely separate periods, their range expansion curves suggest some stability of their ranges in time. Nevertheless, a more rigorous assessment of spatial organisation would require simultaneous tracking of several individuals.

Male M2 had a greater nightly range and rate of travel than the other 2 otters, probably because of he was searching for mates. For example, he travelled most quickly in the river which provided access to females in different parts of his range. Furthermore, his rate of travel in the river was lower for sessions with vocal meetings than for those without, suggesting a possible social function (eg search for mates). Patterns of temporal range use also suggested differences in searching behaviour; M2 regularly patrolled his range, whereas M1 was relatively sedentary moving occasionally between two core areas. This latter pattern may be typical for young or subordinate otters, yet to establish a stable range (Erlinge 1968, Kruuk and Moorhouse 1991).

All 3 otters used the streams within their total ranges more than expected from the areas available. This could be explained by their use of a linear habitat characteristic, constant with respect to width (eg banks). Indeed, there were more sightings of otters swimming close $(<1 \mathrm{~m})$ to the banks than would have been expected had the width been used uniformly. It was unlikely that this was due to an observation bias, as otters were usually more conspicuous in midstream areas than at the margins (L. S. Durbin, pers. obs.). This habit of foraging close to the banks may allow otters to monitor olfactory cues at defaecation sites. Such behaviour would be particularly advantageous to reproductive males, as estradiol levels in the urine of female otters can signal sexual receptivity (Gorman and 
Trowbridge 1989). Otters may also experience greater foraging success at the margins than in open water, as their well-developed tactile sense (Green 1977) enables them to remove prey from riparian refuges with ease (L. S. Durbin, pers. obs.). Furthermore, in tributaries, brown trout appear to recolonise areas more quickly following depletion (D. Carss, unpubl.), than Atlantic salmon (Armstrong et al. 1994). If this is a genuine species-specific phenomenon rather, than an environmental one (eg habitat or season-related), it may explain the patterns of otter utilization observed. In the Don catchment trout dominate the streams and margins of the river (regions used by otters in greater proportion than the areas available), whereas salmon dominate central regions of the river and wide tributaries (Durbin 1993, B. Shields, pers. comm.). Although deep sections of the river cannot be electrofished effectively, there is no evidence that fish are more abundant in the streams than the river (Durbin 1993). Renewal rates and availability may therefore have greater effects on otter movements than absolute prey abundance, but further electrofishing studies are needed to evaluate this.

Generally the 3 otters foraged in transit, but fed more intensively when they apparently detected a dense prey patch (L. S. Durbin, pers. obs.). Their low tendencies to revisit areas during tracking sessions (on average animals made 1.1-1.3 visits/section) may indicate their avoidance of areas that they had recently depleted, disturbed, or checked for mates. Judging from electrofishing samples, and the locations of nightly foraging patches (Durbin 1993), prey abundance in the Don catchment can vary greatly in space and time. The unpredictability of resource (food patches or mates) availability may therefore necessitate a large nightly and total range, as well as allowing for spatial overlap between ranges (Macdonald 1983). In con- clusion, sexual selective pressures appear to have important influences on the patterns of range use observed. Further research is required to assess the importance of riparian margins, and their apparent influence on otter range size.

Acknowledgements: Thanks are due to many landowners for allowing me to radio-track, and to Drs H. Kruuk and D. Carss for their constructive comments on earlier drafts. I am grateful to 'Care for the Wild' for financial support.

\section{References}

Aebischer N. J. and Robertson P. A. 1992. Practical aspects of compositional analysis as applied to pheasant habitat utilisation. [In: Wildlife telemetry remote monitoring and tracking of animals. I. G. Priede and S. M. Swift, eds]. Ellis Horwood Ltd., Sussex: 285-293.

Alldredge J. R. and Ratti J. T. 1986. Comparison of some statistical techniques for analysis of resource selection. Journal of Wildlife Management 50: 157-165.

Armstrong J. D., Shackley P. E. and Gardiner R. 1994. Redistribution of juvenile salmonid fishes after localised catastrophic depletion. Journal of Fish Biology 45: 1027-1039.

Chanin P. R. F. 1985. The natural history of otters. Croom Helm, Beckenham, Kent: 1-179.

Durbin L. S. 1993. Food and habitat utilization of otters (Lutra lutra L.) in a riparian habitat. Ph D thesis, University of Aberdeen, Aberdeen: 1-118+9. 
Durbin L. S. (in press). Some changes in the habitat use of a free-ranging female otter Lutra lutra during breeding. Journal of Zoology, London.

Erlinge S. 1967. Home range of the otter Lutra lutra L. in southern Sweden. Oikos 18: 186-209.

Erlinge S. 1968. Territoriality of the otter Lutra lutra L. Oikos 19: 81-98.

Foster-Turley P., Macdonald S. M. and Mason C. F. 1990. Otters, an action plan for their conservation. IUCN Species Survival Commision, Gland: 1-126.

Gorman M. L. and Trowbridge B. J. 1989. The role of odour in the social lives of carnivores. [In: Carnivore behaviour, ecology and evolution. J. L. Gittleman, ed]. Chapman and Hall, London: $57-88$.

Green J. 1977. Sensory perception in hunting otters, Lutra lutra L. Otters: Journal of the Otter Trust: $13-16$.

Green, J., Green R. and Jefferies 1984. A radio-tracking survey of otters Lutra lutra (L., 1758) on a Perthshire river system. Lutra 27: 85-145.

Kruuk H., Carss D. N., Conroy J. W. H. and Durbin L. 1993. Otter (Lutra lutra L.) numbers and fish productivity in rivers in north-east Scotland. Symposia of the Zoological Society of London 65: 171-191.

Kruuk H., Conroy J. W. H. and Moorhouse A. 1987. Seasonal reproduction, mortality and food of otters Lutra lutra L. in Shetland. Symposia of the Zoological Society of London 58: 263-278.

Kruuk H. and Moorhouse A. 1991. The spatial organisation of otters (Lutra lutra) in Shetland. Journal of Zoology, London 221: 621-637.

Macdonald D. W. 1983. The ecology of carnivore social behaviour. Nature 301: 379-384.

Mares M. A., Willig M. R. and Bittar N. A. 1980. Home range size in eastern chipmunks, Tamias striatus, as a function of the number of captures: statistical biases of inadequate sampling. Journal of Mammalogy 61: 661-669.

Melquist W. E. and Hornocker M. G. 1983. Ecology of river otters in Idaho. Wildlife Monographs. 83: $1-60$.

Neu C. W., Byers C. R., Peek J. M. and Boy V. 1974. A technique for analysis of utilisation-availability data. Journal of Wildlife Management 38: 541-545.

Powell R. A. 1979. Mustelid spacing patterns: variations on a theme by Mustela. Zeitschrift für Tierpsychologie 50: 153-165.

Sandell M. 1989. The mating tactics and spacing patterns of solitary carnivores. [In: Carnivore behaviour, ecology and evolution. J. L. Gittleman, ed]. Chapman and Hall, London: 164-182.

White G. C. and Garrot R. A. 1990. Analysis of wildlife radio-tracking data. Academic Press, London: $1-383$.

Received 11 September 1995, accepted 19 March 1996. 